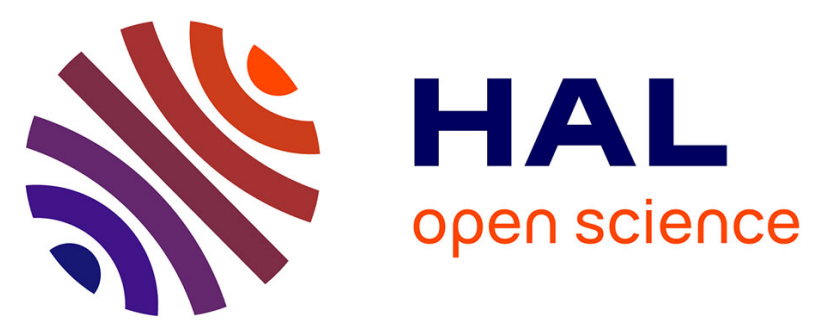

\title{
Organizational Designs for Sharing Environmental Best Practice Between Manufacturing Sites
}

\author{
Lampros Litos, Peter Lunt, Wen Liu, Steve Evans
}

\section{To cite this version:}

Lampros Litos, Peter Lunt, Wen Liu, Steve Evans. Organizational Designs for Sharing Environmental Best Practice Between Manufacturing Sites. IFIP International Conference on Advances in Production Management Systems (APMS), Sep 2017, Hamburg, Germany. pp.427-434, 10.1007/978-3-319-669267_49. hal-01707271

\author{
HAL Id: hal-01707271 \\ https://hal.inria.fr/hal-01707271
}

Submitted on 12 Feb 2018

HAL is a multi-disciplinary open access archive for the deposit and dissemination of scientific research documents, whether they are published or not. The documents may come from teaching and research institutions in France or abroad, or from public or private research centers.
L'archive ouverte pluridisciplinaire HAL, est destinée au dépôt et à la diffusion de documents scientifiques de niveau recherche, publiés ou non, émanant des établissements d'enseignement et de recherche français ou étrangers, des laboratoires publics ou privés. 


\title{
Organizational designs for sharing environmental best practice between manufacturing sites
}

\author{
Lampros Litos ${ }^{1}$, Peter Lunt ${ }^{2}$, Wen Liu ${ }^{1}$, Steve Evans ${ }^{1}$ \\ ${ }^{1}$ Institute for Manufacturing, University of Cambridge, CB3 OFS, Cambridge, UK \\ ${ }^{2}$ Airbus Limited Ltd, BS34 7PA, Bristol, UK
}

\begin{abstract}
Development and sharing of environmental best-practice manufacturing has been studied extensively in the literature. Most studies have focused on areas such as: inter-/intra-organizational relationships, supply chain collabo-rations and networking capabilities. However, little attention has been paid by academia and practitioners to the concept of system designs that enable these intended functions. The research gap is quite evident in the case of energy efficiency, especially in multi-site manufacturing operations. This paper explores organizational models that can facilitate the development and sharing of best practice (DSBP) for energy efficiency and the conditions that enable these to be more effective vehicles of improvement. As part of a larger research project on practice maturity for eco-efficiency, the authors conducted semi-structured interviews with industrial practitioners that are directly involved with energy efficiency improvements in two large multi-site organizations. The authors recognize two DSBP organizational models: a) networks of practice (a decentralized approach) and b) model-factories (more linear approach). This study aims to demonstrate the challenges and opportunities that each model brings and narrates the enabling conditions of their adoption.
\end{abstract}

Keywords: best practice sharing, eco-efficiency, maturity

\section{$1 \quad$ Introduction}

Many manufacturing companies operate across multiple sites. The choice of expanding manufacturing operations from a single factory to multiple ones, within the same country or abroad, is a matter of strategic importance and very closely linked with the corporate business strategy [1]. Sustainable manufacturing in this context is defined as a way of making products that eliminates environmental hazards (pollution prevention) and waste in energy and materials [2]. Abdul Rashid et al., identify four sustainable manufacturing strategies that are available to practitioners to explore: waste minimisation; material efficiency; re-source efficiency; and eco-efficiency. Achieving improved energy and resource utilization by following one of those strategies is also a matter of scalability for multi-site manufacturing operations. It is logical to assume that the faster and better improvements are developed and replicated across sites, the higher the gains for the environment and the business. Existing techniques to reduce manufacturing variability may be applicable to eco-efficiency but researchers show that there may be 
complementarity with more focused efforts to reduce environmental impacts [3]. Nevertheless, there is evidence that a performance gap exists between factories, within multi-site operations, in energy and resource efficiency [4], [5]. The study here also serves as a response to information silos and local or fragmented development of best practice in manufacturing [6], [7].

\section{Methodology}

This study is concerned with the mechanisms that mature manufacturing companies deploy to develop and share environmental best practice across these factories. The research question that this paper explores is: "How do multi-site companies develop and share environmental best practice (DSBP)?" This study draws theoretical grounds from the resource based view of the firm, extended by Hart to account the natural environment [8]. Understanding how to best utilize resources and internal capabilities can be a driver for improvement and lead to competitive advantages [9]. This work here is part of a larger research plan based on Design Research Methodology that seeks to generate practical support for energy and resource efficiency in manufacturing [10]. The authors conducted interviews with environmental management practitioners in two multinational corporations in Europe in the automotive and aerospace sectors that operate 9 and 11 factories respectively ( 8 interviews and energy efficiency workshop with 11 delegates). The interviews were exploratory in nature to gain rich perspectives of the way that DSBP is approached in these companies [11]. Both companies pursue environmental best practice at process level in their factories, they are both ISO14000 accredited and have been actively involved in common research activities for eco- efficiency [12]. The interviewees were people in charge of environmental management in factories, with a wealth of experience in developing and sharing of best practice (lean, operational, environmental).

\section{The case studies}

\subsection{The aircraft manufacturer}

This company operates in the aerospace sector and owns 11 manufacturing sites that employ approximately 50000 people across four European countries. Most of the sites are responsible for specific parts of the aircraft i.e. fuselage, wings. These parts once manufactured are sent to two final assembly sites. Developing energy efficiency solutions in manufacturing has practically been a major issue for the company for several years. It has not been until 2006 that a corporate policy was developed that would formalize the efforts towards energy efficiency and set a $20 \%$ reduction in energy by the year 2020 across all manufacturing sites. The year 2006 became the baseline year for energy savings and performance measures. The resources available for the implementation of improvements were based on lean practices, manufacturing engineering implementations and research and development (R\&D). A business case for each project is a necessary part of the improvement process and it helps to assign responsibilities 
and accountability to the people in charge of the improvements. However, energy efficiency improvements at process level (i.e. the painting process) did not necessarily adhere to a strategic improvement program. A recent study in this company identified a set of barriers to energy efficiency such as (Peter Lunt et al., 2014): lack of accountability, no clear project ownership and no sense of urgency to improve. It was agreed in 2012, that to replicate and scale up localised improvements across the sites, a process of cross-plant coordination was required. The company had previously done this when seeking to harmonise its manufacturing processes through international process technology groups within the manufacturing engineering function (Lunt et al., 2015). This approach consists of each plant nominating a representative who takes the lead and coordinates activities. The same approach was applied to the creation of an industrial energy efficiency network.

In the second half of 2012, each plant was asked to nominate a representative. Notably in this case the representatives of the industrial network came from a range of functions: industrial maintenance (5), manufacturing engineering (3), lean operations (1), health \& safety (1), facility management (1) [5]. It is expected that the industrial network would contribute to a significant $7 \%$ share out of an over-all $20 \%$ energy reduction target for the year 2020. The network's operations are further facilitated with typical corporate resources available, such as online tools that help practitioners report and track the progress of current projects, review past ones and learn about best-available techniques. On average, a 5-10\% time allocation is ap-proved for all network members to engage with the network functions. In case a member is not coping in terms of time management there is the option of sub-contracting the improvement project to an external subcontractor who is hired for that particular purpose and the subcontractor's time allocation to the project can be up to $100 \%$. "By having the network we meet and we select together a list of projects that we want to put forward to access central budget. So we know roughly how much capital will be allocated to industrial energy efficiency and so we select projects across all of the sites that we think will get funded and we support them all together as a group, instead of having lots of individual sites making individual requests for funding and being rejected. We go together as a group and have some kind of strategy as well."

Most of the network members also act as boundary spanners [13] in the sense that they have established connections to process technology groups or they are members of these groups too. These boundary links help the net-work establish strong communications with other functions within the organization and act as conductor for information flows. This type of social capital has been shown to improve performance by enabling employees to access the resources that are embedded within a given network and by facilitating the transfer and sharing of knowledge [14].

\subsection{The automotive manufacturer}

The automotive company is a global leading Japanese manufacturer and a lean management pioneer. The company actively pursues environmental and social sustainability improvements and other companies find their methods inspirational or exemplar [5], [15]. The interviews were held with the environmental and social responsibility general 
manager for Europe and one of their factory managers in the UK. The company has been continuously improving on various environmental indicators and they feel that a level of proactive sustainability thinking already lies within the staff. The company operates 9 factories across the broader European region with some of them making engines and transmissions that are then shipped to the other car assembly factories. In terms of environmental performance improvements, the UK plant, for example, between 1993 and 2013, reduced its energy usage per vehicle by over $70 \%$. In the same period, it also reduced water use per vehicle by over $75 \%$, and waste produced per vehicle by nearly $70 \%$ [16]. In terms of developing and sharing of best practice this company applies the concept of the model factory. Two factories in Europe have been assigned by top-management the role of model factories for energy (UK) and water efficiency (France) respectively. The decision to assign the title of a model factory to those sites made further business sense (i.e. the cost of energy in the UK is a potent driver for energy efficiency).

An example of how this model works is described in the case of energy efficiency improvements. The energy efficiency improvement was focused on the plant's control systems in the paint booth process. An opportunity to improve was at hand but the financial risk of failure to achieve the perceived benefits was unbearable for the model factory's budget. However, the environmental and social responsibility general manager for Europe decided to fund the trial in one of the several paint booths in the UK model factory: "We need to make the step change. This is the amount of money we will pay. We will invest this money one time in one booth only in UK as our model plant". The fact that the UK site was already nominated as a model factory made the decision easier to justify and manage. The results were satisfactory and the plant managed to improve paint-booth energy-efficiency by $40 \%$. The improvement was then justifiable at plant level and carried out in all the plant's paint booths, thus achieving better scales of efficiency. Through standardization and kaizen activities the results became the efficiency norm in the paint booth processes. In addition, the achievement was communicated through intra-organizational networks in the company and this was then replicated in other sites that the improvement was relevant.

Another function that the model factory may serve is technology management. For example, the model factory in the UK serves as an improvement hub and testbed for more conventional technologies. The French site is the newest one in Europe and therefore serves as a hub for advances in manufacturing technology. The distinction makes it easier for top-management to decide where to allocate resources and address specific issues related to technology improvements. Even though there may be local budget per site for improvements, there is a budget range that could be considered too risky without a model factory to test it first. Without a model factory, plants may be in internal competition to secure central funds for improvements.

\section{Conceptualisation of DSBP models and discussion}

The case studies describe two distinct pathways for energy efficiency improvements across manufacturing sites. The first one is the "industrial network" and the second one 
is the "model factory". The observations in these cases have produced the conceptualization of models to develop and share environmental best practice (DSBP) across manufacturing sites. In this section, these DSBP models will be described as processes that deliver eco-efficiency improvements across multiple sites. It is the author's intention to conceptualise these processes to industrial practitioners and academics and raise considerations about the way that improvements can be aligned to systemic capabilities. It needs to be noted that the authors here, focus less on the development stage of best practice and focus more on the process of sharing best- practice to other sites as the literature gap tends to be less popularised in the literature with case studies

In the following figure the DSBP models are graphically described through three scenarios where an improvement has been developed and tested in one of the plants (i.e. site A) and can be replicated across sites with confidence. The word scenario is used to describe the situations and avoid confusion with DSBP models and model factory. In each scenario, the authors assume that the information related to the improvement can have multiple receptors. The scenarios that describe the DSBP models are compared to a default scenario 1, where information silos and poor communication links between sites inhibit replication of improvements and knowledge transfer.

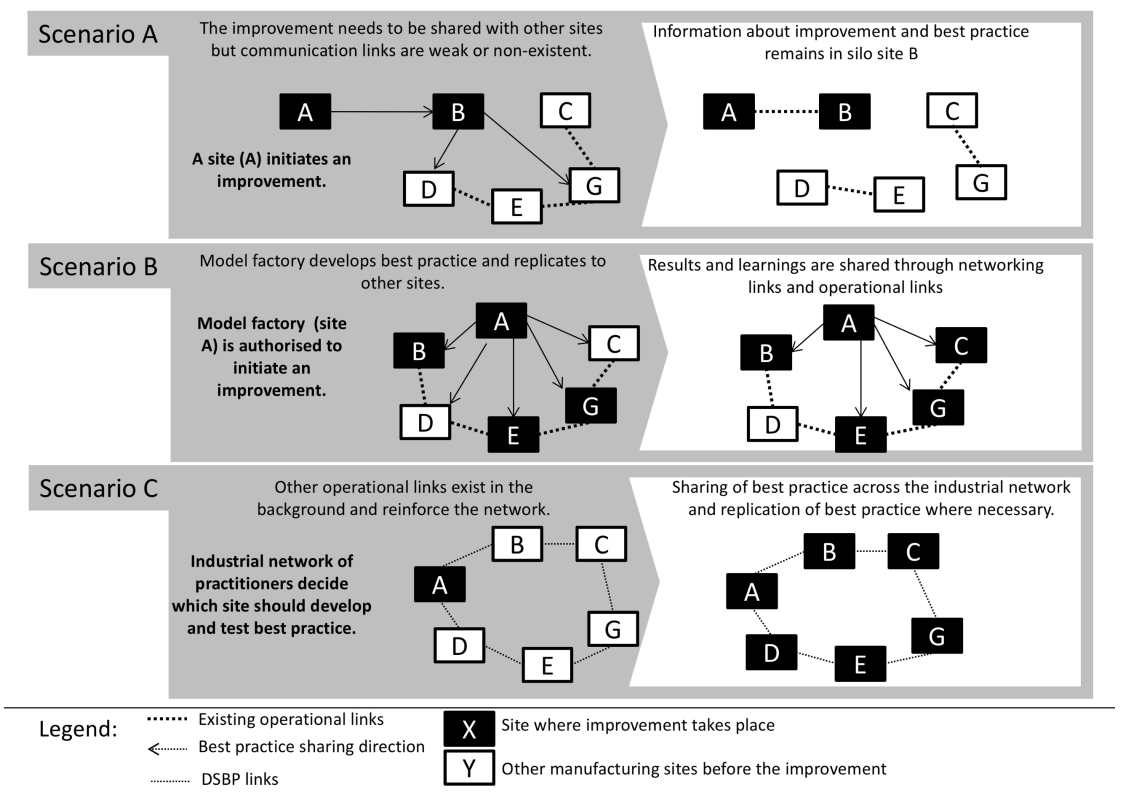

Fig. 1. Demonstration of SDBP models in three scenarios

Scenario A. .: the information silos: This scenario represents the "business as usual" case, where little attention is paid to the way that plants share knowledge and information with each other. It offers a contrast to the authors arguments Information flows would follow the operational links between the factories (i.e. material flow through internal logistics - parts being shipped between factories). Figure 1 demonstrates how some of the sites will be carrying out the improvement that has been suggested by site 
A and little will be known about this in other manufacturing sites because of weak communication flows that do not stretch beyond operational efficacy.

Scenario B: the model factory: The second scenario is a prototype-based approach where a manufacturing line or factory is selected by top-management to be- come a best-practice centre of excellence for other factories. Lessons learned are replicated vertically rather than horizontally in other sites by expert staff and re- ported back to top-management through typical communication routes. This scenario may incorporate some networking activities to advertise achievements horizontally across the organization. However lateral sharing of best practice could be controlled through formal communication and reporting processes. The suggested improvement is tested in the model factory with centrally authorised funding, thus reducing financial risks and system friction (easy to choose where to make the test). The solution may be relevant to other sites (if successful) and will be replicated quickly through their own allocated budgets with confidence. Some sites may not be affected (i.e. site D in the figure 1) and there is some risk in regards to finding out about the improvement. In the case study in the automotive, attention is paid to lateral information sharing and this should be another consideration for using this DSBP model.

Scenario C: the industrial network: The third scenario is a network-based approach where practitioners of common practice goals, form networks that nurture the development and sharing of best practice. Lateral information sharing is amplified and reaches people that may not be directly involved in projects or have any immediate shared interest. The network is supported by informal attitudes between its members and a sense of trust enhanced by common goals that the network pro- motes throughout the business. In this DSBP model, an improvement is identified by one site or brought forward by a networking activity (quarterly meetings). This is added to a collection of improvement projects and the network commonly agrees to prioritize the projects based on success factors, financial risk or urgency. Central budget may be raised with supporting procurement processes (i.e. economies of scale to introduce better equipment across many sites rather than just one). The network financially supports the implementation of the solution in one of the plants and the benefited plant feeds the knowledge and benefits gained, back to the net- work. All plants are informed and further actions are developed (this time, site $\mathrm{D}$ is being informed even though the solution was not relevant to its operations, as D is represented in the network).

The industrial energy efficiency network is not the only network that operates within the aircraft company. For example, in March 2015 a network to improve gender balance in the workforce was launched. It was confirmed from the energy network leader that this is a common practice in the company as it is a way of keeping all sites in- formed about new projects and maintain a level of harmonisation in practices. It is a practice that has been nurtured over the years and is used to promote collaboration and communication internally and across sites. It was confirmed from the energy network leader that he made a conscious choice not to choose an energy-model architecture. He saw the network as a better cultural fit for that activity instead of promoting the site he worked at as the energy efficiency model factory. Compared to the aircraft company, the automotive relies more on their core capabilities of standardisation and continuous improvement to sustain networking functions internally and across remote sites. 


\section{Conclusions}

The authors observe that there are two distinct approaches to development and sharing of best practice in parallel to a more "business-as-usual" approach. The distinction aims to demonstrate the organizational design and the cultural differentiators between these two approaches. A manager may choose to use these models in different conditions. One of the managers in the automotive noticed that: "...so I think there is a blend to it to be taken or where would we use the network approach as a principle way of sharing and where we use the model plant of sharing something and I think that is a distinction that I will probably make. The sharing and network approach we tend to use for things that are locally developed by members, they make some kaizen on the line or do some activity that reduces some environmental impact. That is recognised within the plant and it is brought to be shared in the committee or the working group meeting. The model plant idea is to say we are trying to go away from this small incremental change to go towards a more step-change."

The manager illustrates that there are various possible routes to develop and share best practice and furthermore the DSBP models can be complimentary to each other and can interplay. The authors' contribution to theory and practice is founded on the observation that organizational properties and priorities may favour one approach over the other. Resource-based view theory supports the argument that companies tend to rely on system strengths to respond to new challenges. From the case studies here, this assumption seems to be verified. However, it needs to be noted that the companies examined are considered to be quite mature in terms of the practices they tend to employ in operations. Both "model factory" and "networks of practice" exhibited improvement potential. It is outside the scope of the study to examine the speed of the improvements achieved as this may vary across industries and whether low hanging fruits in terms of energy and resource efficiency have already been reaped. In summary, the key contributions of this study are:

1. Manufacturers may choose to utilise DSBP models to implement and share best practice in multiple manufacturing sites. These conceptual models can help companies reduce the risk of developing solutions to energy and resource efficiency.

2. Managers should align the choice of these models by considering not only the environmental and economic benefits but also the cultural fit with the organization. Enhanced fitness may enable a more efficient dissemination of best practice and thus generate more value for stakeholders.

\section{References}

[1] Y. Shi and M. Gregory, "International manufacturing networks - to develop global competitive capabilities," Journal of Operations Management, vol. 16, no. 2-3, pp. 195-214, May 1998.

[2] S. H. Abdul Rashid, S. Evans, and P. Longhurst, "A comparison of four sustainable manufacturing strategies," International Journal of Sustainable Engineering, vol. 1, no. 3, pp. 214-229, 2008. 
[3] W. C. Lucato, M. V. Júnior, and J. C. da S. Santos, "Measuring the ecoefficiency of a manufacturing process: a conceptual proposal," Management of Environmental Quality, vol. 24, no. 6, pp. 755-770, 2013.

[4] L. Litos and S. Evans, "Maturity grid development for energy and resource efficiency management in factories and early findings from its application," Journal of Industrial and Production Engineering, vol. 32, no. 1, pp. 37-54, Jan. 2015.

[5] P. A. V. Lunt, P. D. Ball, and S. Kaladgew, "Integrating Energy Efficiency into Industrial Strategy - A Case Study from the European Aerospace Sector," Procedia CIRP, vol. 26, pp. 241-246, 2015.

[6] O. Boiral, "Tacit Knowledge and Environmental Management," Long Range Planning, vol. 35, no. 3, pp. 291-317, Jun. 2002.

[7] C. N. G. Proches and S. Bodhanya, "An Application of Soft Systems Methodology in the Sugar Industry," International Journal of Qualitative Methods, vol. 14, no. 1, pp. 1-15, Jan. 2015.

[8] S. L. Hart and G. Dowell, "Invited Editorial: A Natural-Resource-Based View of the Firm Fifteen Years After," Journal of Management, vol. 37, no. 5, pp. 14641479, Sep. 2011.

[9] J. B. Barney, "Resource-based theories of competitive advantage: A ten-year retrospective on the resource-based view," Journal of Management, vol. 27, no. 6, pp. 643-650, Dec. 2001.

[10] L. T. M. Blessing and A. Chakrabarti, DRM, a Design Research Methodology. London: Springer London, 2009.

[11] R. K. Yin, Case study research - Design and methods, 3rd ed. Thousand Oaks: Sage Publications Ltd, 2003.

[12] P. D. Ball et al., "Factory Modelling: Combining Energy Modelling for Buildings and Production Systems," in Advances in Production Management Systems. Competitive Manufacturing for Innovative Products and Services, C. Emmanouilidis, M. Taisch, and D. Kiritsis, Eds. Springer Berlin Heidelberg, 2013, pp. $158-165$.

[13] J. H. Gittell and L. Weiss, "Coordination Networks Within and Across Organizations: A Multi-level Framework*," Journal of Management Studies, vol. 41, no. 1, pp. 127-153, Jan. 2004.

[14] D. Z. Levin and R. Cross, "The Strength of Weak Ties You Can Trust: The Mediating Role of Trust in Effective Knowledge Transfer," Management Science, vol. 50, no. 11, pp. 1477-1490, 2004.

[15] J. Dyer and K. Nobeoka, "Creating and Managing a High Performance Knowledge-Sharing Network: The Toyota Case,” Jul. 2002.

[16] S. B. Hope, "Encouraging Inter-factory Learning," presented at the 2nd Annual Conference for the EPSRC Centre for Innovative Manufacturing in Industrial Sustainability, Cambridge, 10-Sep-2013. 